\title{
Archives, Aesthetic Dimensions, and Academic Identity
}

\author{
Ellyn Lyle, Yorkville University \\ elyle@yorkvilleu.ca
}

Cecile Badenhorst, Memorial University of Newfoundland

cbadenhorst@mun.ca

\author{
Heather McLeod, Memorial University of Newfoundland \\ hmcleod@mun.ca
}

\begin{abstract}
Three authors offer a methodological bricolage to explore visual, textual, and poetic archives that shape our identities as women academics. We draw on aspects of autoethnography, reflexively engaged, to explore these archives as they lend insight into the construction of personal identity. Understanding both the archives and identity as inseparable from culture, we take up cultural analysis as historical method as we examine, through archival metaphor, the historical struggles of women in academia. We believe that scholarly writing within disciplinary contexts is one way that women can constitute identity for ourselves and, in so doing, find pathways to write our way into existence.
\end{abstract}

Keywords: Women scholars; academic identity; autoethnography; arts-informed research.

\section{Ontological, Epistemological, and Individual Context}

Historically, academe has been regarded as a male space owing to the assumption that knowledge is masculine (Brown et al., 2015; Lyle \& MacLeod, 2016). Further complicating this inequity is the tendency of leadership to favour authoritarian perspectives largely associated with male ways of knowing (Matheson \& Lyle, 2017; McGee, 2013; Taber, 2011, 2015). As women academics struggle to negotiate hospitable professional spaces, they are often pulled between conflicting senses of self. Scholarly writing within disciplinary contexts is one way that women can employ agency against patriarchy to author their own sense of self (McLeod \& Badenhorst, 2014). Situating ourselves within the critical qualitative paradigm, we offer a methodological bricolage (Lyle, 2018a, 2018b) to explore visual, textual, and poetic archives that shape our identities as women academics. Reflexively, we explore personal art-archives for insight regarding the historical struggles of women in academia.

Critical qualitative inquiry (CQI) is firmly rooted in the pursuit of social equity (Denzin, 2017). Specifically, it has at least five central purposes: it places the voices of the marginalized at the heart of inquiry; it uses inquiry to reveal possibilities for activism; it employs inquiry and activism to help underrepresented groups; it informs social policy; and it issues a call for socially responsible transformation (Bloom \& Sawin, 2009). Committed to these purposes, critical qualitative scholars have tended to reject the traditional qualitative agenda (Denzin, 2017; St. Pierre, 2017a; St. Pierre, 2017b) that resides in paradigmatic ideology in favour of a reflexive engagement that examines the ontological and epistemological implications of the self's claims of knowledge. By interrogating how individuals create their realities as they study them, reflexive 
inquiry requires that we address critical questions about the essence of reality, the construction of knowledge, and the ways we engage with each other and society (Burkinshaw \& White, 2017; Cunliffe, 2016). Navigating the intersection of self and society encouraged us to include autoethnography as a central strand in our methodological braid. Not only is this approach consistent with our critical approach, we understand autoethnography as both a mode of inquiry and as a way of knowing (Bochner \& Ellis, 2016; Ellis et al., 2011). That is to say that autoethnography is an epistemological endeavour that is supported by a dynamically dual process: it requires that we look inward at the vulnerable self in relation to its cultural context even as it encourages us to look outward and consider the social and cultural aspects of our lived experiences (Bochner \& Ellis, 2016). Approaching inquiry from this perspective allows researchers to understand impressions of self in terms of social contexts (Hickey, 2016). Within this framework, we turned our attention to selfhood and explored identity construction as a situated activity.

\section{On Self \& Identity}

While it is beyond the scope of this paper to wander too far down the social psychology path, a little background is helpful. Much of the literature in education pertaining to identity tends to discuss it from one of two historical perspectives: identity theory (see Stryker, 1980); or social identity theory (see Tajfel \& Turner, 1979). At its most basic, Identity Theory (IT) focuses on the intersection of social structures and identities while assuming that individuals develop identity based on role choice within these social contexts (Stryker, 1980). Social Identity Theory (SIT) holds that identities are formed collectively and based on perceived value assigned to these collective groups (Tajfel \& Turner, 1979; Trepte \& Loy, 2017). Developing out of SIT, SelfCategorization Theory (SCT) was proposed by Turner (1999) and distinguishes between social and personal identity. Specifically, SCT argues that an individual's behaviour is influenced by its relative significance to the personal or social identity of any given situation (Trepte \& Loy, 2017). SCT defines individuality with regard to identity but stops short of the possibility that it is personal rather than role-based. While both identity theorists and social identity theorists consider personal identity in their general discussions, neither incorporates it in a significant manner (Hitlin, 2003). Personal identity theory, in contrast, is a micro-sociological theory that understands identity as a unique sense of self constructed over time and evidencing continuity, integration, identification, and differentiation from an individual rather than group perspective (Hewitt, 1997; Hitlin, 2003). This sense of self is understood in terms of its relationships and responsibilities rather than in relation to a community or group. Because the emphasis in analysis is on the individual as they navigate various roles, personal identity embodies the social psychological model of a self that is influenced by its interaction with society. Bukor (2011) summarizes it particularly well:

personal identity theory deals with how people categorize themselves as they act out a particular role and how they can incorporate the meaning and the expectations associated with that role into their identity...thus, personal identity may be viewed as identification with specific roles that are played out in a social setting by an individual from the individual's perspective. (pp. 67-68)

Epson (2013) reminds us that, as we negotiate our identities in response to our social interactions, we construct identity in hindsight incorporating past and present understandings of self with our hopes for our future development. In this way, personal identity is the dynamic manifestation of autoethnographic processes:

individual identity is an expression of the meaning that each of us attaches to ourselves and a reflection of the meaning that others attach to us. We are 
therefore engaged in an ongoing struggle to create a coherent sense of self within this shifting context as we construct, repair, maintain, and review our identities. (p. 231)

\section{On Self \& Identity - as Women in Academia}

Allowing for the impact of roles, relationships, and responsibilities on identity development, it seems important that we look at self and identity from the perspective of being women in academia. Because the epistemological structure of higher education does not favour the collaborative ways of knowing that females have traditionally been socialised to embrace, institutions of higher education are not regarded as gender neutral. Said another way "women academics' participation in higher education institutions is hindered by the social identity that others construct for them" (Maphalala \& Mpofu, 2017, p. 9247). Even as women academics struggle to shape their identities personally, as well as in context, they are necessarily part of a collective identity against which their successes are measured. Pulled between often conflicting senses of self in a largely patriarchal world, women more frequently experience identity crises (Yilmaz, 2014). Scholarly writing within disciplinary contexts can help women constitute identity for themselves and, in so doing, find pathways to write their way into existence (McLeod \& Badenhorst, 2014).

\section{Ceclie}

I'm cleaning out the mounds of paper I've collected over my tenure years. Now on sabbatical, the urge to house-clean is overwhelming. Without remorse, I assign hundreds of sheets of outdated teaching notes, useless administrative trivia, and obsolete research projects to the recycle bin or the shredder. My fingers touch my $11 \times 9$ daily planner from 2014 and stop. The plastic cover is an old friend; I know it well. Rooting around, I find that I have kept planners for every year I have been in this job. In these diaries are the endless to-do lists, the precious $C V$ achievements, the battles for positioning within the faculty. I don't open any of the diaries but I won't throw them away. I place all eight of them in the bottom drawer of my filing cabinet. There they will stay, the pile growing incrementally each year, never to be opened again but somehow always connected to me, like an umbilical cord. The diaries are a source of pride, an achievement of survival but, also, a source of trauma. As Cvetkovitch, (2003) notes: "the memory of trauma is embedded not just in narrative but in material artifacts" (p.7). Sometimes these arbitrary artifacts are invested with enormous emotional value.

In this archive, the pages record social interactions, connections, and collaborations but they also contain silences - the scribbled notations and absent marginalia that I don't speak or share, the prayers breathed onto the pages, and the trembling fingers that smoothed the paper looking for solace. It's the maternal body that is silenced in these texts. The professional body is loud, confident, and self-possessed but the maternal body is barbed wire wrapped, unsteady, and quaking. The many years of swimming practice times, upcoming exams, and the daily minutia of teenage lives are inscribed here alongside the neurologist and neuro-surgeon appointments, the MRI's, and the EEG's and finally the surgery schedule. The yearning, dread, and terror that lives alongside the harsh chronic illness of a child lie unvoiced but present in these texts. Only the closest of friends know and even they don't know the daily grind of keeping going, being productive, and fitting in. The Promotion \& Tenure files of which much data is drawn from these planners extoll a successful career, but underneath it all is a heavy silence - an absence that is all too present. 


\section{Archives, Past Selves, and Present Narratives}

Archives as a concept has stirred the imagination of scholars across a broad range of disciplines (Bradley, 1999). The common definition of the archive is a repository or a collection of artifacts that has been teased, tested, and transformed. As Manoff (2004) suggests, the term is "loosening and exploding" (p.10). It is a slippery concept that has multiple manifestations (Bradley, 1999). The interpretative spectrum of archives is bracketed by two extremes: literalism and abstraction. Literalism holds that the field of archival studies ought to focus on collecting, cataloguing, and curating historical documents (Ernst, 2004). Here, archives must be deemed culturally and socially important enough to be preserved and are valued not as a collection of primary sources, but as streams of data (Badley, 1999; Manoff, 2010). Abstraction advocates for situatedness and maintains the archive can be understood as ideas, imaginaries, discursive gatherings, and sites of knowledge production (Manoff, 2004). Even personal memory processes are included for their ability to create internal mental archives where we store significant events, symbols, and ideas (Mori, 2011). What draws our interest in this latter conceptualization is the inclusion of personal collections. The shoeboxes and biscuit tins shoved under the bed and the old suitcase buried under trivia in the attic containing the "flotsam of individual life" (Hobbs, 2001, p. 131). Ordinary people preserve and curate their own personal records over the span of their lives, keeping what is significant to them and discarding the rest.

Personal archives provide "glimpses of inner soul as well as outer manifestation" of individual lives and personalities (Hobbs, 2001, p. 126). Not all individuals keep personal archives and seek to create a record, but those who do invest highly subjective meanings into their preserved texts (McKenzie \& Davies, 2012). These documents, while always under threat of instability, are highly intertextual. In other words, these texts interact with other texts, both past and present. A personal diary, for example, is embedded in a broader social web of interconnected documents, songs, poems, or visual artifacts. Sometimes these personal archives are systematic and orderly and, other times, they are chaotic and random; they are always embedded, though, in deeply meaningful interpersonal relationships (McKenzie \& Davies, 2012). Preserving bits of the self is a "site of multiple constructs - of a persona upholding and struggling with ideas, of self and of others, while simultaneously contradicting, convincing and contriving" (Hobbs, 2001, p. 132). Personal archives provide witness to our existence, activities, experiences, and relationships with others where we leave behind "the comforting marker-buoys and trail signs" of our lives (McKemmish, 1996, p. 181).

\section{Cecile}

I have another archive in my home, one that developed over the years of coping with a child's chronic illness. I always attend academic conferences from beginning to end and add a few days on either side of the conference for sight-seeing. On the sight-seeing days, I visit fleamarkets. Indeed, I spend as much time researching local flea markets as I do preparing for the conference. The conferencelflea-market visits have become a symbiotic relationship where the conference is almost meaningless without the flea market. I'm drawn to small odd items. After a conference in Amsterdam, I found a collection of seven handmade wooden birds, each no bigger than a small coin as well as a pair of faded miniature clay dolls (now, very shabby) with their hands clasped on their chests; I also found a wooden singing nun about $2.5 \mathrm{~cm}$ high that had been part of some bigger collection. The vendors were surprised that anyone would want to pay money for these items and one even waved away my $25 \mathrm{c}$ with a shake of his head. Nonetheless, I bring 
my treasures home and place them in labelled boxes in my craft room. They are for my eyes only, and I rarely show them to anyone else.

While browsing through the boxes now, I notice that although I collect many different items, I'm drawn to dolls. From South Africa, I have small Xhosa, Zulu and other African dolls; from Japan, tiny Kokeshi dolls, and many other miniature wooden dolls whose countries of origin are lost to me. The magic, for me, is the variety and imperfection. Chipped paint, faded colours, and broken bits of characters create a combination that transport me out of this world into the doll's world, which is only limited by the extent of my mind. Touching, sorting, and staging these dolls seems to decompose and leach much of what the black, coffin-like diaries construct in me. Through these dolls, I imagine I can be someone different, imperfect, damaged, flawed, perhaps still silenced, but present, in a more peaceful way for just this moment. In this moment, the fear is on hold, behind me, out of sight. Dolls characteristically are imbued with human attributes, and there seems to be something magical about this human-like representation (Donaldson, 2012). My maternal body finds solace here with this magic and in this delightful imaginative space.

\section{Figure 1}

Cecile's Planners and dolls: Imaginative crossings. Badenhorst (2018)

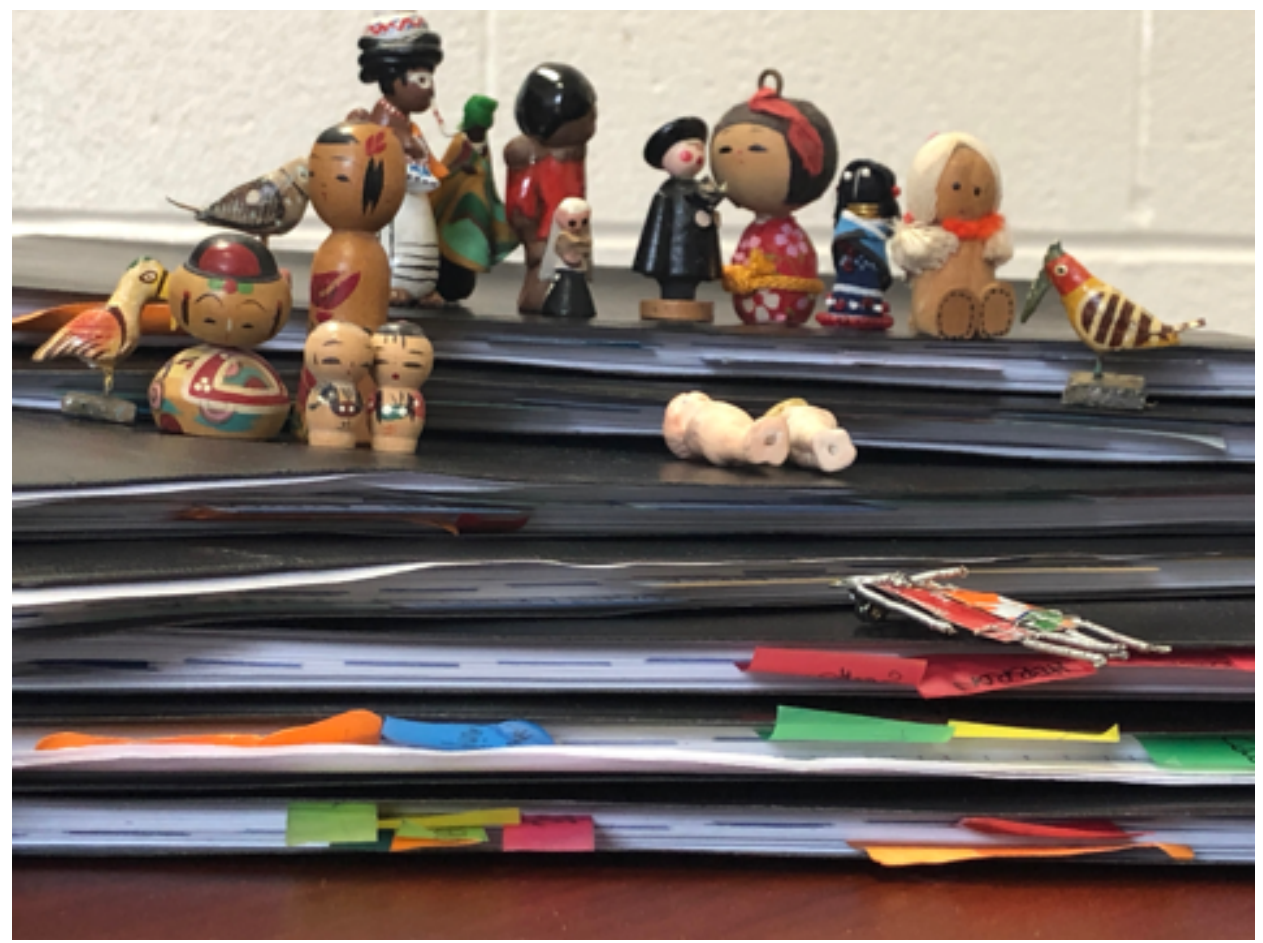

How we interpret these personal archives, whether they are abstract or literal, is a subject of intense debate. Looking back on the past is an intimacy of rememberings and forgettings and is thus fraught with contestation. "The archive is a repository of memories" argues Bradley (1999, p. 108). Through the archive, we attempt to recover lost stories - we "reconstruct, restore, recover the past" (Bradley, 1999, p. 109). Bradley describes sorting through her mother's effects some months after her mother's death. This personal archive offered her the story of her own past as a child as well as her mother's "pleasures, pains and losses" (p. 166). The tactile, tangible collection of scraps and relics made lost voices real again. Ernst (2004), however, argues that the archive is 
not a place of memory; it is merely a space for storing texts. Where the texts may once have been thrown out, they are now ordered and preserved. They may contain traces of symbolically coded matter but the archive itself does not tell the story - quite the opposite, it is full of "holes and silences" (Ernst, 2004, p. 3). We fill in the gaps with imagination. This also holds true for history. As Munslow (2010) urges, we must recognise the "fictive narrative construction of history" (p. 74). Historians decide what to include and also make judgements about gaps. The past and memory is re-imagined as a composite narrative, a narrative created from the discrete bits of recorded texts, sounds, images, or recollections (Ernst, 2004). Similarly, both personal and official archives are neither neutral nor innocent but contain the distortions of the powerful and the absent-presence of silenced voices (Manoff, 2004). That is to say that there is no archive without the substrate of memory because the archive constructs historical memory even as it stores it (Barnet, 2001). Despite all of this, archives do have a connecting thread: narrative memory, and it is this thread that we continue to explore here.

\section{Heather}

As a feminist artist/scholar, I acknowledge my personal values influence my academic work. Poet and educator Carl Leggo (2011) writes, "poets remind, see, reveal, listen, remember, startle, imagine, tease, question, pray, hope, linger, love, and connect" (p.57) and, from a young age, I've carried with me a mental archive of poetic phrases and song lyrics (cf. Pickett, 2017). Family, school, and everyday life shape my mental architecture - often literally bequeathing to me the songs I sing. The images and rhythms comfort me and help me make new meaning as I advance through the years.

As a five-year-old, I won a prize for my recitation of "I Meant to Do My Work Today" by Richard Le Gallienne (n.d.):

I meant to do my work today-

But a brown bird sang in the apple tree, And a butterfly flitted across the field,

And all the leaves were calling me.

And the wind went sighing over the land,

Tossing the grasses to and fro, And a rainbow held out its shining hand-

So what could I do but laugh and go?

Imagine a serious and sturdy child who has never attended Kindergarten or school. Tutored weekly by my elocution teacher and supported by my approving mother, I learned the poem by listening and repetition until I knew it by heart. In a community hall, I passionately expressed these views as my own. I couldn't read yet but was already espousing resistance to the 'work ethic' as I understood it from listening in on adult conversations. I identified with that poem. It seemed to me to mark an understanding I shared with my mother. Indeed, I recently used it at her memorial service. When I matured, it was the words from "The Summer Day" by Mary Oliver (1992) that brought me joy.

Who made the world?

Who made the swan, and the black bear?

Who made the grasshopper? 
This grasshopper, I mean-

the one who has flung herself out of the grass,

the one who is eating sugar out of my hand,

who is moving her jaws back and forth instead of up and downwho is gazing around with her enormous and complicated eyes. Now she lifts her pale forearms and thoroughly washes her face.

Now she snaps her wings open, and floats away. I don't know exactly what a prayer is.

I do know how to pay attention, how to fall down into the grass, how to kneel down in the grass

how to be idle and blessed, how to stroll through the fields, which is what I've been doing all day.

Tell me, what else should I have done?

Doesn't everything die at last, and too soon?

Tell me, what is it you plan to do with your one wild and precious life?

Oliver's final line, "with your one wild and precious life" is evocative. My father's life was wild, precious, and far too short; he's long gone now. On rereading the two poems, the images and meanings fuse together. I can view both at the same time - as if Oliver's (1992) work is a new map drawn on tracing paper and laid over Le Gallienne's (n.d.) vintage guide. There is a certain symmetry between them. One pattern slides over the other. I create a found poem using their words only. First, I chose an image from Le Gallienne's verses, and then a corresponding phrase from Oliver's. The rhythm and resonance of the words help clarify my values and emerging thoughts.

\section{Pattern on Pattern}

\section{Today, summer day, laugh. \\ Flung out gazing around \\ Shining and blessed.}

The grasses-fall down into the grass!

Across the field, through the fields

Wind sighing over the land, grasshopper eating sugar out of my hand.

I meant to do my work-but, too soon idle

A rainbow floats away... Doesn't everything die at last?

So what could I do? Tell me, what else should I have done?

Go, pay attention

Figure 2

Calling, she lifts her pale forearms, she snaps her wings open-wild and precious life.

Pattern on Pattern. McLeod (2019). 


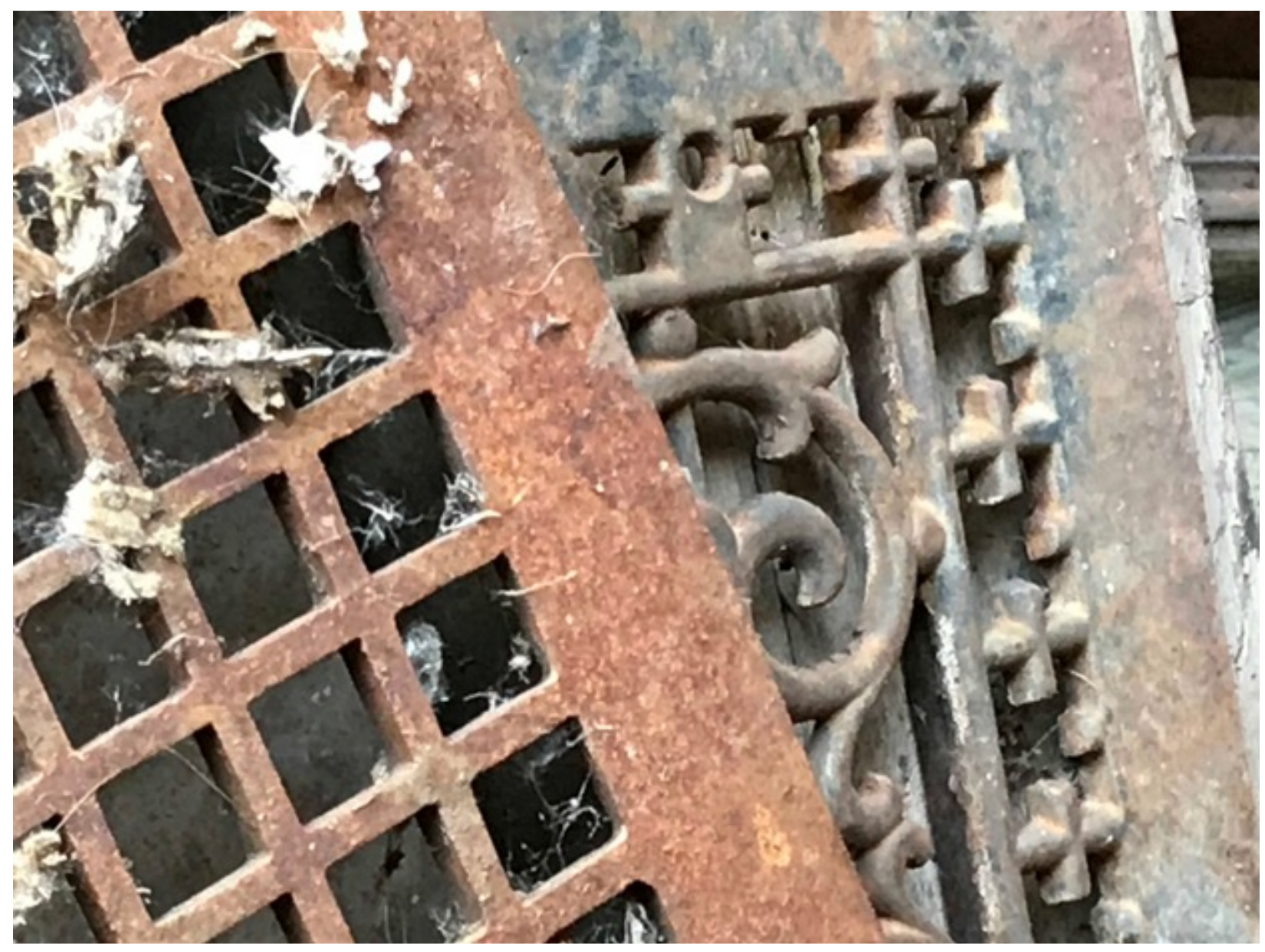

Both Le Gallienne (n.d.) and Oliver (1992) call me to pay attention. Oliver adds the complexity of acknowledging death. My found poem is about work, joyous response to the natural world, and the transitory nature of our days. It's about life and death. I am shaped by the arts, and I create new understandings. My archive of poems and songs continue to teach and sustain me as a daughter and as an artist/scholar. This is important. Rather than merely do my work, I've learned to attend to it.

Archives are indeterminate things. They usually contain an accumulation of documents or artifacts saved over the course of a lifetime. The reasons for selecting the specific contents are largely unique, though the intent is invariably to preserve. In considering our topic, we let our minds wander as we thought about issues, evidenced through the arts, that span nations. Our cerebral wandering quickly turned specific and we wondered in earnest about the struggles (both historical and continuing) of women in academia as they attempt to navigate identity development.

\section{Ellyn}

Understanding personal archives as providing unique perspectives on arts-based historiography, I began sifting through my stored remembrances to see what inclusions shed light on my identity as a woman academic. I unearthed a treasure-trove of bits and bobs that had resonated with me over the years, but I eventually settled on three specific inclusions collected or 
created during the 25 years since I entered academe for the first time. Each speaks to a core constituent of my identity.

A Commencement Address.

In the fall of 1993, I left my community of 500 and moved to Halifax to attend Mount Saint Vincent university, a small liberal arts school with a 90\% female student body. I acknowledge that the pervasive feminist undertones of The Mount wore on the 18-year-old me who never really felt the sting of oppression. The second of three daughters, each of us was encouraged to be strong and independent and accountable. I suspect that's why Adrienne Rich became my first mentor in this new place. She took the form of a wise, if unforgiving, auntie who challenged me to be more. I first encountered her work in a literature survey course and honestly don't remember what of hers it was that I read. I do know that it resonated with me enough that I looked for other things she had written. It was then that I stumbled upon her Claiming an Education speech. Delivered as the commencement address at Douglass College in 1977, it hit all the cords for me: the inseparability of teaching and learning; the importance of authoring my own life without being pigeon-holed into roles created for me; and the impossibility of speaking to women's advancement while excluding men from the conversation. In all these enduring lessons, Rich (1977) taught me to think in verbs: that I must claim an education even as I interrogate who wrote the texts and for what purposes. She insisted that women and minorities were largely erased from the curriculum as men continued to decide what counted as legitimate knowledge. This could only end, she coached, when we took responsibility for and toward ourselves:

Responsibility to yourself means refusing to let others do your thinking, talking, and naming for you; it means learning to respect and use your own brains and instincts. It means that you do not treat your body as a commodity with which to purchase superficial intimacy or economic security; for our bodies to be treated as objects, our minds are in mortal danger.... It means that you refuse to sell your talents and aspirations short, simply to avoid conflict and confrontation. And this, in turn, means resisting the forces in society that say women should be nice, play safe, have low professional expectations, drown in love and forget about work, live through others, and stay in the places assigned to us. It means that we insist on a life of meaningful work, insist that work be as meaningful as love and friendship in our lives. It means, therefore, the courage to be "different"; not to be continuously available to others when we need time for ourselves and our work; to be able to demand of others-parents, friends, roommates, teachers, lovers, husbands, children - that they respect our sense of purpose and our integrity as persons. Women everywhere are finding the courage to do this, more and more, and we are finding that courage both in our study of women in the past who possessed it, and in each other as we look to other women for comradeship, community, and challenge. The difference between a life lived actively, and a life of passive drifting and dispersal of energies, is an immense difference. Once we begin to feel committed to our lives, responsible to ourselves, we can never again be satisfied

with the old, passive way (Rich, 1977).

I felt as though Rich (1977) was speaking directly to me - that she had issued a call to action, challenging me to live fully and unapologetically, not despite my womanhood, but because 
of it. She left a fire in my belly as I internalized her challenge as a defining characteristic of my identity.

\section{A Photograph.}

Many years after the fire lit by Adrienne Rich, I encountered in the woods what seemed to me the embodiment of the historical and continuing struggle of women. It was the day after a particularly angry autumn storm, and I headed outdoors to see if there was much damage to the woods or the coastline. As I walked the south boundary of the property, there she stood. I was captivated. I walked around her, taking in her unyielding endurance, and found myself wishing she could speak to me. Arms raised to the sky, her femininity exposed, she was reaching for something. Noting her severed head hanging backward, beautiful cascade of hair still trailing behind her, I believed she was channeling the fire to reclaim her wholeness.

\section{Figure 3}

\section{“Warrior Goddess.” Lyle (2019)}

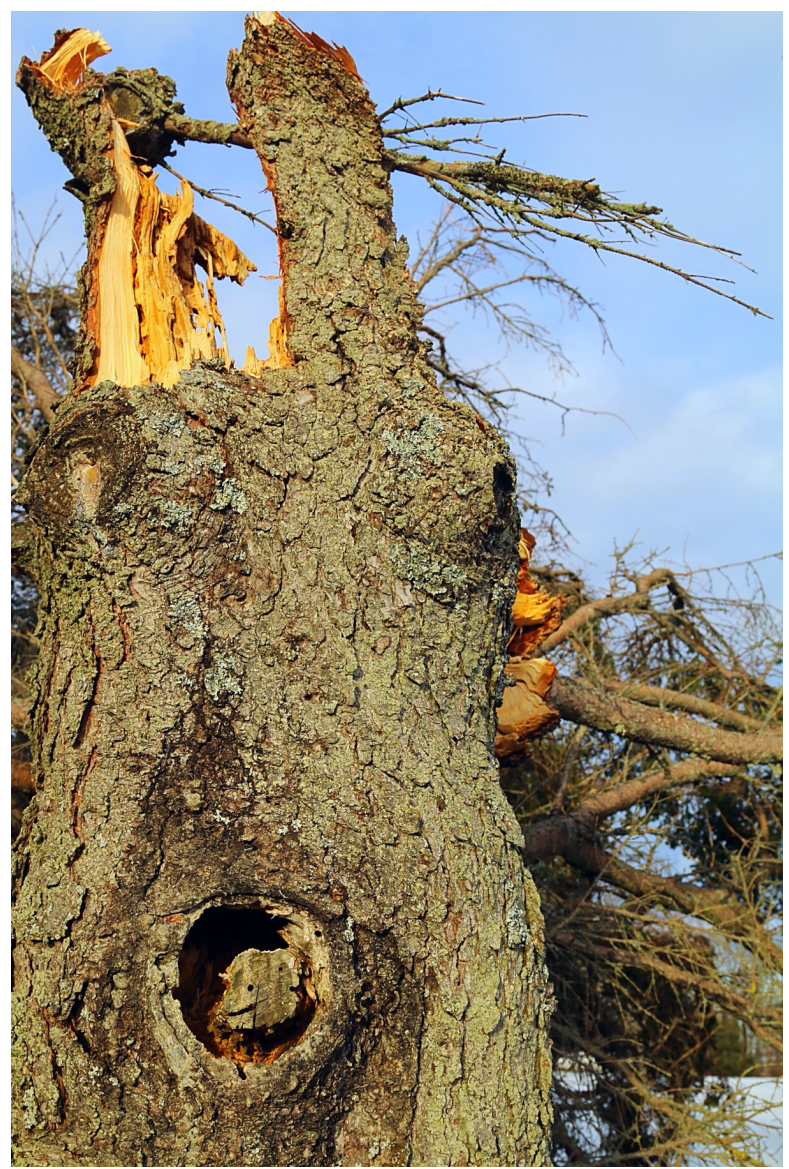

\section{A Poem}

I'm 45 now - not old, I guess, but not so young anymore, either. I've come to understand during the last 25 years in academe the pervasive patriarchy that continues to father us, love us, cajole us, and bully us into desired behaviour. I have learned to pick my battles, to identify those 
proverbial hills worth dying on, but I do so vocally and unapologetically as I try to name what feels unjust and remain relevant long enough to make some small difference. I am still learning to live out loud, seeking that delicate balance of speaking my reality in a way that can be heard. I am committed to nurturing that fire that sometimes burns a bit hot, believing it is the only fuel that can propel us forward. In the spirit of that relentless movement, I close with a favourite poem:

$$
\begin{aligned}
& \text { this is } \\
& \text { an overdue } \\
& \text { love letter } \\
& \text { to each } \\
& \text { \& every } \\
& \text { woman } \\
& \text { who walked } \\
& \text { these fields } \\
& \text { before me } \\
& \quad \& \\
& \text { made } \\
& \text { the path } \\
& \text { soft enough } \\
& \text { for me to } \\
& \text { walk through } \\
& \text { to get to } \\
& \text { the side } \\
& \text { they could } \\
& \text { never reach. } \\
& \text { for that, } \\
& \text { i owe you } \\
& \text { so much. }
\end{aligned}
$$

- but I owe some things to myself, too.

(Amanda Lovelace, 2018)

\section{Closing Contemplations}

In this methodological bricolage, we explore visual, textual, and poetic archives that have shaped us as women academics. We have taken up the concept of personal archives to engage in an exploration of people and things, specifically regarding the aesthetic dimensions of our everyday academic subjectivities. These personal archives provide tactile, tangible collections that reveal secrets, lost voices, and relics of emotions but can also provide insight regarding cultural contexts in which the personal is experienced. Of course, we acknowledge both history and our subsequent constructions are fictively construed and necessarily impressionistic, yet arts-based histories provide a provocative means to explore ethical, moral, and ideological values that write their way into our constructed identities. In sifting through our personal archives, we acknowledge the everyday experiences that shape us, our work, and our identities. Through archival artifacts, 
we individually and collectively explore the aesthetic dimensions of our identities as women academics. We view autoethnography as more than a methodology: it is a mode of inquiry and a way of being. It requires us to be vulnerable and, through that vulnerability, connect to broader social stories. In the spirit of autoethnography, we move between the personal and the sociopolitical in an attempt to weave new insights into the identity tensions women wrestle within academe. We do so as an invitation to think with us about historical struggles related to women academics and to suggest pathways to new consciousness.

\section{References}

Barnet, B. (2001). Pack-rat or amnesiac? Memory, the archive and the birth of the Internet. Continuum: Journal of Media \& Cultural Studies, 15(2), 217-231.

Bloom, L. R., \& Sawin, P. (2009). Ethical responsibilities in feminist research: Challenging ourselves to do activist research with women in poverty. International Studies of Qualitative Studies in Education, 22, 333-351.

Bochner, A., \& Ellis, C. (2016). Evocative autoethnography: Writing life and telling stories. Taylor and Francis.

Bradley, H. (1999). The seductions of the archive: Voices lost and found. History of the Human Sciences, 12(2), 107-122.

Brown, A., Adams, B., Filardo, E-A., \& Richards, K. (2015). Impacts of culture and leadership on gender integration and operational effectiveness in male dominated environments. DND Press.

Burkinshaw, P., \& White, K. (2017). Fixing the women or fixing universities: Women in HE leadership. Administrative Sciences, 7(3), 30. doi:

http://dx.doi.org.libraryservices.yorkvilleu.ca/10.3390/admsci7030030

Burton, J. (2017). Foreword. In D. Caraccioli., \& C. Weida (Eds.), The swing of the pendulum: The urgency of arts education for healing, learning, and wholeness, pp. ix - xiv. Sense.

Cvetkovich, A. (2003). An archive of feelings. Durham \& London: Duke University Press.

Cunliffe, A. L. (2016). On becoming a critically reflexive researcher. Journal of Management Education, 40(6), 747-768

Cunliffe, A. L. (2003). Reflexive inquiry in organizational research: Questions and possibilities. Human Relations, 56(8), 983-1003.

Denzin, N. K. (2017). Critical qualitative inquiry. Qualitative Inquiry, 23(1), 8-16. 
Donaldson, J.A. (2012). For the love of dolls: Artifact and identity. [Unpublished doctoral thesis]. School of Art, RMIT University.

Ellis, C., Adams, T. E., \& Bochner, A. P. (2011). Autoethnography: An overview. Forum: Qualitative Social Research, 12(1), 1-19.

Ellis, C., \& Bochner, A. P. (2000). Autoethnography, personal narrative, reflexivity: Researcher as subject. In N. K. Denzin \& Y. S. Lincoln (Eds.), Handbook of qualitative research (2nd ed., pp. 733-768). SAGE.

Ernst, W. (2004). The archive as metaphor: From archival space to archival time. Open! Platform for Art, Culture \& the Public Domain, 1-8. www.onlineopen.org/the-archive-asmetaphor

Hewitt, J. (1997). Self and society: A symbolic interactionist social psychology. 7th ed. Boston: Allyn and Bacon.

Hickey, A. (2016). The critical aesthetic: Living a critical ethnography of the everyday. In S. Steinberg \& G. Cannella (Eds.), Critical qualitative research reader (pp. 166-181). Peter Lang.

Hitlin, S. (2003). Values as the core of personal identity: Drawing links between two theories of self. Social Psychology Quarterly, 66(2), 118-137.

Hobbs, C. (2001). The character of personal archives: Reflections on the value of records of individuals, Archivaria, 52, 126-135.

Le Gallienne, R. (n.d.) I meant to do my work today. Your Daily Poem. http://www.yourdailypoem.com/listpoem.jsp?poem_id=1151

Leggo, C. (2011). What is a poem good for? 14 possibilities. Journal of Artistic and Creative Education, 5(1), 32-59. https://jace.online/index.php/jace/issue/view/17/5\%281\%29

Lovelace, A. (2018). The witch doesn't burn in this one. Andrews McMeel Publishing.

Lyle, E., \& MacLeod, D. (2016). Women, leadership, and education as change. In A. Normore \& T. Watson (Eds.), Racially and ethnically diverse women leading education: A worldview (pp. 7589). Emerald Publishing.

McGee, H. (2013). Leadership advancement in the united states air force: A Delphi method to identify the most effective leadership traits for female senior leaders.

Lyle, E. (2018a). Untangling sel(f)ves through A/R/Tography. In E. Lyle (Ed.).

The negotiated self: Employing reflexive inquiry to explore teacher identity. Brill | Sense, 1-13.

Lyle, E. (2018b). Methodological bricolage: On reflexivity, autoinquiry, and the marginalized self. Qualitative Research Newsletter. AERA. Spring 2018. 
Manoff, M. (2004). Theories of the archive from across the disciplines. Libraries and the Academy, 4(1), 9-25.

Manoff, M. (2010). Archive and database as metaphor: Theorizing the historical. Libraries and the Academy, 10(4), 385-398.

McKemmish, S. (1996). Evidence of me. The Australian Library Journal, 45(3), 174-187. McKenzie, P.J., \& Davies, E. (2012). Genre systems and "keeping track" in everyday life. Archival Science, 12, 437-460.

McLeod, H, \& Badenhorst, C. (2014). Stories of Researcher Beginnings and Becomings. Creative Approaches to Research, 7(1), 67-81.

Maphalala, M. C., \& Mpofu, N. (2017). Are we there yet? A literature study of the challenges of women academics in institutions of higher education. Gender \& Behaviour, 15(2), 9245-9253.

Matheson, I. \& Lyle, E. (2017). Gender bias in Canadian military leadership training. Journal of Ethnographic and Qualitative Research, 12, 18-28

Mori, N. (2011). Where are we going beyond the archive metaphor? Culture \& Psychology, $17(1), 11-19$.

Munslow, A. (2010, n.d.). The future of history. Red Globe Press, 3-4 passim. https://www.culturahistorica.es/munslow/historian_as_author.pdf

Oliver, M. (1992). A summer day. https://www.loc.gov/poetry/180/133.html

Owen, D. (2017). Fireflies: Memory, identity, and poetry. Sense.

Pickett, S. (2017). Fierce love: Fashioning becoming a researcher. The Canadian Review of Art Education, 44(1), 85-100.

Rich, A. (1977). Claiming an education. Working Worlds. http://networkingworlds.weebly.com/uploads/1/5/1/5/15155460/rich-claiming_an_education-1.pdf

Seixas, P. (2017). A model of historical thinking. Educational Philosophy and Theory, 49(6), 593-605.

St. Pierre, E. (2017a). Writing post-qualitative inquiry. Qualitative Inquiry, 0, 00, 1-6.

St. Pierre, E. (2017b). Haecceity: Laying out a plane for post qualitative inquiry. Qualitative Inquiry, 23, 9, 686-698.

Stryker, S. (1980). Symbolic interactionism: A social structural version. Benjamin/Cummings. 
Taber, N. (2011). Ruling relations, warring, and mothering: Writing the social from the everyday life of a military mother. Lambert.

Taber, N. (2015). Women military leaders in the Canadian Forces: Learning to negotiate gender. D. Clover, S. Butterwick, D. Chovanec, \& L. Collins (Eds.), Women, Adult Education, Learning and Leadership in Canada (46-56). Thompson Publishing.

Tajfel, H., \& Turner, J. (1979). An integrative theory of intergroup conflict. In W. Austin \& S. Worchel (Eds.), Psychology of intergroup relations, (pp. 33-47). Brooks/Cole.

Yilmaz, S. (2014). Feminist ideology of an academic woman in Margaret Drabble's The Millstone. Journal of Research in Gender Studies, 4(2), 495-513. 